Article Type:
Original Manuscript (Conceptual)

Corresponding Author:

Bejan D. Analoui, Department of Management, University of Huddersfield, Queensgate, Huddersfield, HD13DH, UK.

Email: b.analoui@hud.ac.uk

\title{
Independent female escorts: stigmatised, value-adding entrepreneurs
}

\section{Bejan D. Analoui}

\section{Dinuka B. Herath}

Department of Management, University of Huddersfield, Queensgate, Huddersfield, UK.

\begin{abstract}
In this article, we characterize an independent female escort (IFE) as a sex worker who provides sexual services and companionship in exchange for remuneration, makes use of the internet for the solicitation of her clients, and solicits those clients and organizes her work in a largely independent manner. We draw on the typology of value-adding and value-extracting entrepreneurship, to argue that the activities of IFEs can be considered as entrepreneurial activity that has clear individual and societal benefits. Despite undertaking value-adding entrepreneurial activity, IFEs, as with other sex workers, often face social stigma and concomitant social exclusion. We argue that such stigma is not warranted, and highlight the opportunities for undertaking research into the manner in which perceived and experienced social stigma may affect the entrepreneurial activity of IFEs.
\end{abstract}

\section{Key Words}

Sex, escort, independent, value-adding, value-extracting

\section{Introduction Prostitution and escorting value-adding and value-extracting entrepreneurship}

Sex work is the provision of 'commercial sexual services, performances, or products given in exchange for material compensation' (Weitzer, 2000:3) and is multimodal encompassing a range of activities, and can be found in a range of settings. Following other studies, it is posited that sex work can be conceptualised and theoreized about as any other form of work (Brewis and Linstead, 2000; Pajnik, 2015). 
Extant literature positions some forms of sex work such as prostitution and escorting as entrepreneurial activity (Heyl, 1979; Brewis and Linstead, 2000; Lucas, 2005; Castle and Lee, 2008; Smith and Christou, 2009; Williamson and Bakers, 2009; Bleakley, 2014; Pajnik, 2015, Griffith et al, 2016). However, with some notable exceptions (see for example, Smith and Christou, 2009), these works do not appear within the entrepreneurial literature but instead are featured in journals concerned with sociological enquiry, criminology and policy. In addition, relatively little attention has been given to the use of the Internet as a method of advertisement, solicitation and as a medium for the engagement and undertaking of sex work more generally (Castle and Lee, 2008; Pajnik, 2015; Griffiths et al, 2016). This is noteworthy, since there is a widespread recognition that the internet has changed the dynamics of sex industry (Bleakley, 2014; Pajnik, 2015; Griffith et al, 2016; Sanders, Connelly and King, 2016), with many activities involving online technologies (Sanders, Connelly and King, 2016). Much of this article is concerned with independent female escorts (IFEs), who drawing on the definitions offered by Koken (2012) and Griffith et al (2016), we characterise as sex workers who provide sexual services and companionship in exchange for remuneration, make use of the internet for the solicitation of their clients, and solicit those clients and organise their work in a largely independent manner. We echo the narrow (e.g. Grffith et al, 2016) and broad calls for additional research into the undertaking of sex work in and through the online context (Castle and Lee, 2008; Pajnik, 2015; Sanders, Connelly and King, 2016), and for a greater focus on forms of prostitution and escorting occurring away from traditional street corners (Weitzer, 2005).

In this paper we seek to accomplish three tasks: First, we argue that sex work can be characterised as entrepreneurial activity. In doing so, we draw on the dichotomy of value-adding and value-extracting entrepreneurship (Frith and McElwee, 2009; McElwee, Smith and Somerville, 2011). In this section we present our principle conceptual contribution: a typology that enables the location of different forms of sex work, according to whether that work is independent or collective, and the extent to which it adds or extracts value from the context in which it is undertaken. Second, we outline that those engaged in sex work such as prostitution (Edlund and Korn, 2002; Sallman, 2010; Krüsi et al, 2016), and as IFEs (Koken, 2012; Sanders, Connelly and King, 2016) often face stigma, and concomitant social exclusion. In this discussion we also explore the moral basis for such stigmitastion. Finally, we highlight some opportunities for engaging in entrepreneurial research into various aspects of the work undertaken by IFEs, and apropos of the aims of this special issue, we focus our discussion through the lens of stigma.

\section{Prostitution and Escorting as Value-Adding and Value- Extracting Entrepreneurship}

Prostitution has aphoristically been referred to as the world's oldest profession (Van Brunschot et al, 1999) and can be defined as 'the act of rendering, from the client's point of view, nonreproductive sex against payment.' (Edlund and Korn, 2002:183). Escorting may encompass prostitution or be restricted to companionship (Koken, 2012; Griffith et al, 2016). Drawing these definitions together with Anderson's (2000:101) 
conceptualisation of the entrepreneurial process 'as the creation and extraction of value from an environment that involves the shift in value from an existing use value to a higher market value', makes it a trivial task to categorise these activities as entrepreneurial. Given that such broad definitions lead to entrepreneurship becoming 'so broad as to be almost undefined' (Anderson and Starnawska, 2008:222), we seek instead to make a more substantial claim: that prostitution and escorting are entrepreneurial activities that can be of individual and societal benefit.

To this end, we draw on the dichotomy (see Fig. 1) of value-adding and extracting entrepreneurship (Frith and McElwee, 2009; McElwee, Smith and Somerville, 2011). Following, McElwee, Smith and Somerville (2011: 49-50), value-adding entrepreneurship is that which '...creates value in excess of that which accrues to the entrepreneurial individual and, as such, includes benefits which accrue to society more broadly.' While value-extracting entrepreneurship '...involves activities that enrich the individual but which impoverish the society within which they occur.'

\section{[Insert Figure 1 around here]}

Categorising activity within this framework requires an understanding of what value (advantage and disadvantage) accrues and decreases to both individual(s) and society. This is more than the simple task of calculating financial gains and losses. The conceptualisation within this dichotomy as we have interpreted it in the writings of others (Frith and McElwee, 2009; McElwee, Smith and Somerville, 2011) is broad enough to encompass the accrual or decrease of a multitude of advantages and disadvantages. To determine whether value accrues or decreases there is a need to understand who is involved, the type and organisation of the activity undertaken, the outcomes of the activity, and the where and when of its taking place. In short, one needs to understand the context of entrepreneurial activity (Welter, 2011; Gaddefors and Anderson, 2017).

The importance of context for understanding entrepreneurship has been well articulated elsewhere (Welter, 2011; Gaddefors and Anderson, 2017) and, as with other forms of entrepreneurship we contend it is of principle importance for our analysis. Indeed, we shall show whether a form of sex work is value-adding or extracting will depend a number of contextual factors, and the recursive link (Gaddefors and Anderson, 2017) in terms of its outcomes, that entrepreneurship has on that context. In what follows, we present some illustrative examples of different forms of value-adding and valueextracting sex work from the literature, drawing out the complexity of the issues, commenting on contextual factors throughout.

Starting with street-level prostitution, two articles neatly illustrate the valueadding and extracting nature of the work, the complex interpersonal relationships involved, and the recursive link with context. Smith and Christou (2009) examine streetlevel pimping and prostitution in the United Kingdom, focusing principally on the city of Aberdeen, underpinned by findings in other British cities, namely, London, Manchester, Hull, Edinburgh (Leith), and Glasgow. Williamson and Baker's (2009) article, provides examples of both value-adding and value-extracting street-level prostitution. They 
studied the working styles of 53 street-level prostitutes in the Midwest of the United States. Both provide evidence of pimp-controlled prostitution, which involves pimps using various forms of coercion to entice prostitutes into sex work, with verbal, physical and other sanctions being offered for non-compliance. Smith and Christou (2009:81) classify such pimps as 'entrepreneurs of violence'. Such work leads to the creation of value, and yet, we may usefully question who the entrepreneur is. If we take the pimp and prostitute as unit of analysis, that is the view that they are the entrepreneurs, then they together with their punters, as Smith and Christou (2009) note, are involved in the creation and extraction of value from their environment. Yet, we would argue that the focus for entrepreneurial analysis in such a relationship is placed solely on the pimp - it is the determination and act of coercing another into activity that creates value, making that the entrepreneurial act. From such a position, do we classify the activity as valueadding or extracting? We suggest the latter, as once the prostitute becomes induced to act and is subjected to coercion or threat of violence then this becomes of detriment to society which by definition, the prostitute is a part of.

Williamson and Baker (2009) shed light on two other forms of street level prostitution: outlaw and renegade. Outlaw prostitution is similarly value-extracting, they accrue financial gain while their clients suffer financial loss, they 'exploit, and even rob their customers ('tricks') during a sexual transaction' (Williamson and Baker, 2009:37). Renegades are explicitly referred to as independent entrepreneurs, and their activities are best described as value-adding. Renegades work independently or collectively in partnership with other girls. They are motivated by an immediate income, they feel a sense of empowerment, and some gain an emotional fulfilment from their working. To a limited extent, they also stimulate the economy by creating work, for example, it was revealed that in response to concerns over violence, some renegades hired others to watch out for them and ensure their safety.

Heyl's (1979) seminal study of Ann, a prostitute, and later Madam of brothels further highlights the complex inter-relationships between various actors, and social institutions in the prostitution industry. Ann's establishment, is referred to as a teaching brothel, in which new prostitutes, supplied by pimps, are trained by Ann. This training includes instruction in sexual technique, but also in 'hustling', that is the sales skills involved in ensuring the clients spends more than the minimum amount. Ann's teaching also extends to the passing on of the norms and values that guide behavior of prostitutes within the world of prostitution, including the reinforcement of coercive relationships with pimps. Ann's activity we classify as value-extracting, she is involved in the coercion of women into sexual acts, and although she offers softer sanctions herself, she does sometimes inform pimps (who may use violence) of breaches of acceptable behavior. We suggest that Ann's brothels are largely a site of value-extracting entrepreneurship given the actions of the police, who regularly raid the brothel. The brothel is an illegal enterprise, involving illegal entrepreneurship: “...the process whereby entrepreneurs supply willing customers with illegal services or products or legal services or products using an illegal process". McElwee, Smith and Somerville (2011:42). If illegal activity leads to the intervention of social institutions (police, law courts etc) and the subsequent expenditure of their resources, then while it may accrue individual benefits this will be at the 
impoverishment of limited societal. Nonetheless, as a site of entrepreneurship, not all that takes place there is necessarily value extracting - examples are given of independent' prostitutes, working in the brothel without coercion.

This draws attention to the recursive link between entrepreneurship and its context (Welter, 2011) and in particular the role of formal institutions. Formal institutional factors such as laws and regulations provide and restrict entrepreneurial opportunity (Welter, 2011) and we suggest that whether sex work is value-adding or extracting is in part determined, as with other entrepreneurial activity, by what Baumol (1990) has called the rules of the game. However, it is not the formal institutions and any subsequent illegality per se that is at issue - but the choice to act upon that illegality with intervention.

Moving the discussion away from street and brothel based prostitution, Lucas' (2005) study examined elite prostitutes who work off the streets in the middle to upper classes of the profession. Lucas undertook open-ended interviews with 30 female American prostitutes in the mid-1990s working on the West and East coasts of America. Her analysis focuses on her participants' views of prostitution as paid work. She identified three broad approaches to work in her sample, some worked to meet a particular form of lifestyle, others to meet particular financial or personal commitments, and the third group perceived themselves as business people. The argument that this is a form of value-adding entrepreneurship can be made along three lines. First, participants noted individual benefits, perceiving their form of work as being no worse and perhaps better than other forms, having a high-income potential, and providing a considerable degree of autonomy and flexibility. Further, it offers opportunities the development of what we would consider to be transferable interpersonal skills when working independently, noting that such women 'find, screen, schedule, and negotiate with clients, collect fees, find and maintain workplaces, manage transportation and other logistics, decide which services to provide, and the like' (Lucas, 2005:520-1). Second, in addition to the satisfaction of clients there are benefits for those who provide workplaces, transportation and similar - i.e. the goods and services that support escorting. Third, indirect social benefits are also evident, since for some of the women in the study, their financial security, autonomy and flexibility allowed them to spend time doing unpaid work that is meaningful for them, such as engaging in voluntary work.

We are confident that the preceding review establishes that prostitution and escorting can be classified as value-adding and value-extracting entrepreneurship; while demonstrating that the notion that prostitution and escorting can be easily and succinctly characterized in toto is flawed. Rather, a more nuanced understanding that takes account of the context of entrepreneurship is required. To assist others in such an endeavor we offer the following typology (see Figure 2) constructed along two dimensions. The first is the extent to which activity is value-adding or value-extracting. The second draws attention to the entrepreneur(s) involved, and its inclusion stems from the recognition that that prostitution and escorting can be a more (Heyl, 1979) or less (Smith and Christou, 2009) organized collective activity involving multiple actors, or one that is largely independent (Lucas, 2005; Koken; 2012; Griffith et al, 2016). 
Typologies are useful and as Bailey $(1994,33)$ has highlighted: 'a wellconstructed typology ... can transform the complexity of apparently eclectic congeries of diverse cases into well-ordered sets of a few rather homogenous types, clearly situated in a property space of a few important dimensions.'

[Insert Figure 2 around here]

Yet, our typology would allow for no such classification of the literature en masse. Instead, it allows for the classification of the findings of studies, that is, the forms of entrepreneurship discovered. This we see as its great advantage. The typology reminds us that there is no simple formula for determining whether an activity is 'value-adding' or 'value-extracting' and rather forces the asking of difficult and complex questions to place an activity within its bounds. This we have shown depends not just on the activity, but the context in which it is performed, and the outcomes that are generated. To accurately characterize activity as value-adding or value-extracting, and individual or collective, involves answering a set of questions including who is involved? Who is the entrepreneur? If individuals are not acting alone, then what are their relationships? To answer such questions, requires a close look at all necessary actors, thus avoiding blanket statements and assumptions, such as street prostitution is bad for society. Indeed, we hold that using the typology overcomes the tendency sometimes found in the literature to focus on one particular aspect context (Welter, 2011), directing attention to a range of important issues.

We now develop the discussion of the role of context by turning to a discussion of stigma, focusing particularly on the experiences and activities of IFEs

\section{Stigma and social exclusion}

Stigma is socially bounded and often reflects prevailing norms and attitudes (Goffman, 1963). We argue that stigma may reduce the extent to which sex-workers accrue value from their work. It is important to recognise that perceptions of sex work generally, and associated stigma, are always located with a socio-historical context. Indeed, as Benoit et al (2017: 51) note, the 'history of prostitution policy is marked by deep tensions among religious leaders, politicians, health professionals, feminists, sex worker activists and their allies'. Further, while the regulatory approach to sex work varies by geographical location, the stigmatisation of sex work is arguably influenced by the dominant approach, which is criminalisation and enforcement (Krüsi et al, 2016). However, broadly, there is evidently a persistent stigma associated with women's participation in sex work (Koken, 2010; Sallman, 2010), and this stigma is a global phenomenon (Scambler and Paoli, 2008).

Social exclusion is a nebulous term (Peace, 2001) and can be conceived of as having multiple dimensions (Peace, 2001; Marlier and Atkinson, 2010). Marlier and 
Atkinson (2010: 285) defines it as 'the involuntary exclusion of individuals and groups from political, economic, and social processes, preventing their full participation in the society in which they live'. That those who engage in prostitution and or escorting are likely to face stigma that prevents their full participation in some aspects of society is well evidenced. Studies highlight stigma amongst street-level prostitutes (Lucas, 2005; Sallman, 2010; Krüsi et al, 2016) and those working independently online (Koken, 2012; Sanders, Connelly and King, 2016) leading in some cases to experiences of social isolation and feelings of loneliness. Evidence concerning the stigma and social exclusion facing those who work independently online is limited (Koken, 2012), arguably due to this being a relatively new phenomenon when compared to prostitutions otherwise long history (Edlund and Korn, 2002). Independent online sex work may enhance experiences and feelings of isolation, since this work can be mediated without the need of a third party (Bernsetin, 2007). Moreover, within the UK, many choose to work in isolation as it could be considered a contravention of The Sexual Offences Act 2003 for two escorts to work in the same environment - further enhancing the likelihood of loneliness (Pitcher and Wijers, 2014). In addition, based on concerns over stigma, sex workers may not reveal their occupation to those outside of their working environment (Day, 2007), and this is despite it not being illegal to work independently as an escort within the UK. Recently, Sanders, Connelly and King (2016) undertook a survey of 240 internet based sex workers in the UK with a view to explore their working conditions. The sample was comprised of mainly IFEs, and among other items, respondents were asked an open question about the three things they most disliked about their work. The second of these was stigma and poor attitudes towards sex work (the first and third being respectively, clients who waste their time, and experiences of violence and dangers of sex work).

Deeper insights into experiences of stigma can be found in Koken's (2012) study of 30 IFEs based in a major US metropolitan city. The study examined perceptions and experience of sex work related stigma, and the strategies used by participants to manage the impact of this stigma on their personal lives. The study revealed number of themes that clearly outline the difficulties faced, which we summarise as follows. First, many participants discussed the fear of being labelled a prostitute, some saw their work as 'marking them for life', inhibiting their potential for relationships and careers. Therefore, these perceptions of stigma also acted as an additional exit barrier to leaving sex work. African American women in the study related stories of discrimination and prejudice at the hands of police officials - and being exposed to moral judgements from these actors. Second, participants discussed Living in the closet, with their anticipation of stigma leading to their hiding of sex work, increasing their social isolation and loneliness. One participant expressed that she wanted to share satisfying aspects of her work with someone but felt unable to do so. Third, some participants engaged in selective disclosure because of past negative experiences. This avoidance coping technique reduced the extent to which some participants would become intimate with all the people in their personal life, with participants choosing to tell some and not others. The final theme was Coming out as sex worker - with positive experiences being reported by a few who were open with others, adopting an approach coping strategy and seeking support. Koken (2012:223) notes that: "Resisting the stigma associated with sex work begins with an internal re-framing of the work. Reimagining the meaning of sex work away from deviancy is the beginning of taking pride in sex work". 
With the evidence for social stigma faced by sex workers established the next question which arises is why does such stigma exist? The primary objection to sex work has been mounted through highlighting the immortality of such activity and how such activity harms the individual and society. However, upon closer scrutiny we argue that the moral arguments against sex work stem from a disregard to both contexts in which sex work take place and the evolution of moral values in society.

\section{The moral argument}

When considering moral values, the primary debate in literature (Gilbert, 1975; Levy, 2014; Shaw and Barry, 2015; West, 2016) pertains to whether morality is objective (remains the same regardless of the individual/society) or relative (changes depending on individual/society). Traditionally moral values were envisaged to be primarily objective (moral realism) and were derived from religious doctrine (Lambek, 2012; Wainwright, 2017). However, when analyzed carefully the evidence suggests that moral values based on religious doctrine do not provide a satisfactory basis for societal morality both ontologically and epistemologically (Cohen, 1993; Graham et al., 2016). However, modern notions of moral realism stem from belief in a few axiomatic moral principles which are considered to be the basis of all other morals. In contrast, modern moral relativists argue that all moral values are largely dependent on factors such as time, place of birth, geography, and upbringing (Bauman, 1995; Anderson, 2014; Horn, 2017). Therefore, the relativists claim that all moral values are relative and pluralistic (Sachs, 2017). However, regardless of whether one is a relativist or a realist in this regard, there is considerable agreement among scholars that modern moral values are discovered (realist view) or developed (relativist view) through societal consensus, are iterative and tend to change over time (Netter, 2017; Harman, 2015; Velleman, 2015).

In moving this thread forward, Sam Harris, (Harris, 2011; Craig and Harris, 2011), Sean Carroll (Carroll 2010; Carroll, 2017) and Richard Dawkins (Dawkins, 2007; Dawkins, 2016) therefore call for morality (realist or relativist) to be qualified primarily by scientific empiricism, where our moral values should be based on scientific inquiry, testability and a sense of pragmatic utilitarianism. Under such definitions, the primary measure whether an activity is moral or immoral boils down to the notions of wellbeing (Killen and Smetana, 2005; Harris 2011).

Thus, activities which increase both individual and societal wellbeing at large are deemed moral while activities which reduce either individual or societal wellbeing are considered immoral (Suikkanen, 2014; Mogilner et al., 2018). The extant literature on wellbeing posits that elements such as psychological wellbeing, meaningful work, personal choice, accomplishments, relationships, and societal wellbeing should be considered when determining the overall wellbeing of an individual or a society (Ryff and Keyes, 1995; Seligman, 2004; Naci and Loannidis, 2015).

\section{Personal Wellbeing}


Whether one takes a realist or a relativist approach to modern morality, the work of IFEs as defined in this paper does not directly violate any of the notions of well-being discussed above. Emerging research shows that sex work can be meaningful, provide a sense of accomplishment, reinforce personal choice and can be enjoyable within certain contexts in line with modern day notions of wellbeing (Stryker, 2012; Hondro, 2013; Corvid, 2015; Gander, 2016). However, on the other hand when considering personal wellbeing, there are well documented cases of both physical and psychosocial risks of sex work (Rekart, 2005). However, these risks vary in degree and volume depending on the type of sex work (Weitzer, 2006; Sullivan, 2010). For example, an IFE who solicits clients purely through the internet, may have relatively less exposure to sexually transmitted diseases in their job environment compared to someone working on the streets. Therefore, we argue that broadly categorizing sex work runs the risk of over exaggerating the risks of some types of sex work while underestimating the risks in others. Furthermore, it should be noted that work-related risk is inherent in all forms of work (Salin, 2015; Harvey et al., 2017) and is not unique to sex work. Some professions are generally riskier than others (Maslach, 1998; Boles et al., 2004) Therefore, when compared to the spectrum of professions available to a modern individual, sex work remains a viable option (Savitz and Rosen, 1988; Sawyer et al., 2001; Bucardo et al., 2004; Lucas, 2005; Weitzer, 2006; Sullivan, 2010; Abel and Fitzgerald, 2012;). Furthermore, with regard to personal wellbeing, the notion of individual choice should be considered. In all modern theories of morality personal choice is considered an important factor for maximizing wellbeing. Thus, we posit that an individual who freely chooses to engage in sex work should not be stigmatised on the basis of their chosen profession.

\section{Societal Wellbeing}

When measuring societal well-being, the degree of one's activity and its alignment with society is a crucial element to be considered. Most arguments against IFEs are mounted through this dimension where it is posited that sex work does not align with current societal notions of wellbeing. Thus, some argue that this could be constituted as value extraction and should be discouraged (Weitzer, 2005; Lucas, 2005; Weitzer, 2006). However, we contest that such non-alignment with current majority societal beliefs should not be grounds to curtail IFEs activity; instead it ought to prompt debate as why such beliefs have taken root in society, and if such beliefs are warranted especially given that such beliefs are the primary cause of the stigma faced by sex workers.

It is indeed true that IFEs activity may not be the most efficient or effective method of maximizing wellbeing in general. However, we contest that this is not sufficient grounds to stigmatise the actors involved. For example, as a society, in general, we do not stigmatise blue-collar workers for not being white collar workers. While it may be true that white-collar workers earn more, have less risky jobs, and have an overall better living standard, as a society we do not consider this alone should be grounds to stigmatise blue collar workers. Such stigmatisation would be akin to ridiculing a coal miner for not being a physicist. The same argument applies to IFEs. While IFEs activity may not be the best way of maximizing wellbeing, they ought to be free of stigma and ridicule as any other profession (Sullivan, 2010; Abel and Fitzgerald, 2012). While we 
may actively encourage people to find progressively better professions we should not stigmatise them just on the basis of their profession when their work does not directly hinder the wellbeing of the actors concerned.

Interestingly, the stigma associated with sex work may reduce the benefits that accrue for society by promoting informal entrepreneurship. Informal entrepreneurship can be conceptualized as legal entrepreneurial activity that only deviates from accepted rules on the basis that it is undeclared, occurring off the books (Williams and Nadin, 2010). We note that income being undeclared, does not necessitate value-extraction in our typology, but does limit the extent to which value accrues to society. However, it should be noted that not all actors engaged in sex work necessarily face stigma (Lucas, 2005; Koken, 2012).

Since engagement in sex work can be concealed (Koken, 2012; Sanders, Connelly and King, 2016) associated stigma need not bar active and non-stigmatised participation in other areas of social life. Indeed, Lucas' (2005) notes the myriad social involvements of a number of women working as what she terms high class escorts - supported by the financial security, autonomy and flexibility of their work. Thus, such activity might be a route to social inclusion. We now outline potential avenues of enquiry in relation to stigma and independent female escorting.

\section{IFEs and stigma: A review of research possibilities}

IFEs may be of particular interest to researchers for a number of reasons: First, relatively little attention has been given to the use of the internet as a method of advertisement, solicitation, and as medium of engagement with and undertaking of sex work more generally (Castle and Lee, 2008; Pajnik, 2015; Griffiths et al, 2016). Second, IFEs are more likely to be engaged in value-adding rather than value-extracting entrepreneurship since they are not coerced, being by definition, agentic individuals voluntarily engaging in their work. Thus researchers may be able to achieve positive societal impact by determining how such activity can be enhanced. Third, there is a range of practice to explore. As described in previous sections the IFE is responsible for the majority of the organization of her work and has to master, and make use of a variety of business related skills. Fourth, there is little detailed examination of the stigma faced by IFEs (Koken, 2012), and therefore, its impact on entrepreneurial activity. In line with the aims of this special issue, we consider opportunities for investigating choices made with respect to entering in to, engaging in, and exiting work as an IFE.

While others have explored motivations and factors leading to engagement in prostitution and escorting (Heyl, 1979; Lucas, 2005; Williamson and Baker, 2009), there is scope for determining the motivation for engaging in independent activity online, as opposed to joining organised sex work more generally (for example through an agency or brothel). The relative importance of different factors might be considered, such as the desire to run one's own business, have greater control over one's activity (Lucas, 2005; Willamson and Blake, 2009), the safety of pre-screening clients, or the potential for avoiding stigma through concealing activity (Koken, 2012) from others. Concealing is 
easier online, for example, in the advertisement of services since the provision of pictures that allow for identification may be withheld. While these are a common feature of online profiles (Castle and Lee, 2008; Pajnik, 2014), it is currently unclear whether pictures that allow identification necessarily increase custom, and this could be determined. It could also be explored whether concerns over expected stigma might also reduce willingness to diversify into other forms of online sex work. Thus, those wishing to conceal their activity as an independent escort may not wish to engage in (for example) the 'camgirl' industry. As described by Bleakley (2014), this is an interactive form of online sex work, in which sexual performances are offered to clients via the internet, and those watching can interact and sometimes direct the activity of the performer. Distinguishing between those who enter sex work as an IFE, and those who have previously engaged in other forms of sex work will be important. A study by Sanders, Connelly and King's (2016) revealed that the majority of IFEs in their sample had been involved in other aspects of sex work, and tended to engage in different forms of sex work. Thus, we might ask whether perceptions and experiences of stigma in other forms of sex work motivate individuals toward working as IFEs to enhance concealment. Conversely, it could be questioned whether having embarked upon work as an IFE, there is a reduction in perceived expectation of stigma, leading to engagement is less concealed forms of sex work.

The extant literature demonstrates different perceptions of identity amongst those involved in prostitution and escorting (Heyl, 1979; Lucas, 2005; Williamson and Baker, 2009) and the role of personal identity as factor for engaging in sex work of this kind might be explored. For example, if one has already attained a deviant identity such that one perceives oneself to be outside of usual society (Becker, 1963) does this reduce barriers to entry into this form of work? That is to say, does the person who sees themselves as deviant fear associated stigma less? The nexus between identity (say as a businesswoman/call girl/prostitute), regulatory factors, and expectations and actuality of stigma may also be worth investigating. For example, does the perception of one-self as a businesswoman increase willingness to be 'out' as an IFE where regulatory conditions permit? Evidence from Canada suggests that despite normalisation of escorting through licensing, there was still evidence of stigma from various sources (Maticka-Tyndale, Lewis and Street, 2005).Under such circumstances, a consideration of whether perceived stigma results in engagement in informal as opposed to formal entrepreneurship would also be worthwhile. Following from this, it is also worth investigating whether those who are 'out' tend to perform better economically than those who choose to conceal their work.

While stigma and concomitant social exclusion can be directed at IFEs, stigma is also associative. Thus, the escort herself is not the only viable unit of analysis, when considering entry into such work and the choices made thereafter. Indeed, as Welter (2011) has noted, the household and family context is often not explicit in entrepreneurial research, and exploring perceptions of sex work amongst the friends, family, and significant others in the escort's social environs may prove fruitful. For example, it might be asked whether neutral and encouraging attitudes lead to greater entrepreneurial success or less. It could be posited that since stigma is a prevailing concern (Koken, 
2012; Sanders, Connelly and King, 2016) its absence provides time and energy for dealing with business matters.

Researchers may also wish to determine how IFEs learn to undertake the various business related activities involved in their work. It is recognised that entrepreneurs learn in multiple ways, including learning from their own experiences and learning from others (Cope, 2005). If, as suggested in the previous discussion, IFEs typically work alone, and do not discuss their activities, then it is worth considering what their dominant forms of entrepreneurial learning are. Of course, since IFEs may adopt covering strategies when engaging in other areas of social life (Koken, 2012), it is likely that some will engage widely with education and training establishments, participate in networking events, and similar. Similarly, research that undercovers the motivation to engage in business related training, the extent of such activity, and the types of business related knowledge most necessary to succeed as an IFE, would be of value to training and educational providers.

Finally, while there is a long history to prostitution (Edlund and Korn, 2002) - the advent of solicitation on the internet is a relatively new phenomenon (Castle and Lee, 2008). Thus, there is the possibility of undertaking longitudinal research to determine how what are often very public advertisements (Castle and Lee, 2008; Pajnik, 2015; Griffith et al, 2016) impact on the economic prospects and lives of those who are 'out' as independent escorts in the future. Certainly, there is a perception amongst some IFEs that they are tainted by their involvement in sex work, reducing their career prospects (Koken, 2012). However, since the work provides transferable skills (Lucas, 2005) it may be valuable for those seeking an exit from escorting if there was a wider understanding of how prospective employers perceive their work and resulting skillset. In addition, the question of propensity for engaging in future entrepreneurial activity could be considered - to what extent do failed and successful experiences of this form of entrepreneurship lead to the willingness to engage in other entrepreneurial activity within or without of sex work?

\section{Limitations to this discussion}

We have avoided a number of pertinent issues in this piece. First, we have largely ignored a discussion of feminist perspectives on prostitution. We have adopted the position that sex work can be theoreized and conceptualised as any other work (Brewis and Linstead, 2000; Pajnik, 2015), and argued that it can also be entrepreneurial in nature. Wider considerations of ideology, we believe to be outside of the scope of this work. Second, this piece has been focused on female sex workers, and readers may question why male sex workers have been absent from this work. We note that a good deal of the extant literature that explores aspects of sex work in the online context typically reveals larger samples of female sex workers (Castle and Lee, 2008; Sanders, Connelly and King, 2016), and thus the majority of online sex workers may be female. Nonetheless, it is recognised that there are often differences between the working practices, perceptions and experiences of male and female sex workers (see for example, Ellison and Weitzer's 2016 examination of the differences between male and female 
street-based prostitutes in Manchester, UK), and we expect that explorations of male sex workers' entrepreneurial activity in the online context will be as fruitful.

\section{Conclusion}

In this article, we have presented a typology for characterizing sex work that draws attention to the complex nature of this form of work, and the close attention that must be made to context in determining the nature of the activity and its outcomes. We have sought to demonstrate that the work undertaken by some IFEs, and other sex workers, can be classified as a value-adding activity, having individual and societal benefit. Through the discussion of stigma, we have presented the case that IFE entrepreneurial activity should be freed from societal stimgatisation. While we do not actively encourage IFE activity in this paper, we do posit that that such choices ought not to be devalued on the basis of entrepreneurial value-extraction both in monetary and moral terms. Where they exist, we intend this work to challenge the perceptions which lead to the stigmatisation of sex workers. It is our express hope that this article creates controversy, comment and discussion - and leads to the advancement of entrepreneurial research in this area.

\section{Funding}

The author(s) received no financial support for the research, authorship, and/or publication of this article.

\section{References}

Abel GM and Fitzgerald LJ (2012) 'The street's got its advantages': Movement between sectors of the sex industry in a decriminalised environment. Health, Risk \& Society 14(1): 7-23.

Anderson AR (2000) Paradox in the periphery: an entrepreneurial reconstruction?. Entrepreneurship \& Regional Development 12(2):91-109.

Anderson E (2014) The social epistemology of morality: Learning from the forgotten history of the abolition of slavery. In: Fricker M and Brady M (eds) The Epistemic Life of Groups: Essays in Collective Epistemology. Oxford: Oxford University Press, pp. 74-95

Bauman Z (1995) Life in fragments: Essays in postmodern morality. Oxford: Blackwell.

Baumol, W (1990) Entrepreneurship: Productive, Unproductive and Destructive. Journal of Political Economy 98(5): 893-921.

Becker HS (1963) Outsiders Studies in the Sociology of Deviance. New York: The Free Press. 
Benoit C, Jansson M, Smith M and Flagg J (2017) "Well, It Should Be Changed for One, Because It's Our Bodies": Sex Workers' Views on Canada's Punitive Approach towards Sex Work. Social Sciences 6(2): 52.

Bleakley P. (2014) "500 Tokens to Go Private": Camgirls, Cybersex and Feminist Entrepreneurship. Sexuality \& Culture 18(4): 892-910.

Boles M, Pelletier B, and Lynch W (2004) The relationship between health risks and work productivity. Journal of Occupational and Environmental Medicine 46(7): 737745.

Brewis J and Linstead S (2000) 'The worst thing is the screwing' (1): Consumption and the management of identity in sex work. Gender, Work and Organization 7: 84-97.

Bucardo J, Semple SJ, Fraga-Vallejo M, Davila W and Patterson TL (2004) A qualitative exploration of female sex work in Tijuana, Mexico. Archives of sexual behavior 33(4): 343-351.

Carroll S (2010) Science and morality: You can't derive "ought" from “is.". NPR: 13.7 Cosmos and Culture.

Carroll S (2017) The big picture: on the origins of life, meaning, and the universe itself. Penguin.

Castle T and Lee J (2008) Ordering sex in cyberspace: a content analysis of escort websites. International Journal of Cultural Studies 11(1): 107-121.

Cohen J (1993) Moral pluralism and political consensus. In: Copp D, Hampton J, and Roemer $\mathrm{J}$ (eds) The idea of democracy Cambridge: Cambridge University Press, pp. 270-91.

Joshua Cohen, "Moral Plural ism and Political Consensus," in David Copp, Jean Hampton, and John Roemer, eds., ThIe Idea of Democracy (Cambridge: Cambridge University Press, 1993), pp. 270-91

Cope J (2005) Toward a dynamic learning perspective of entrepreneurship. Entrepreneurship theory and practice 29(4): 373-397.

Corvid M (2015) Moving on from the "happy hooker": why I love my job as a sex worker. Available at: www.newstatesman.com/politics/2015/04/moving-happy-hookerwhy-i-love-my-job-sex-worker (Accessed 19 March 2010)

Craig WL and Harris S (2011) Is the Foundation of Morality Natural or Supernatural. Available at: www.reasonablefaith.org/is-the-foundation-of-moralitynatural-orsupernatural-the-craig-harris (Accessed 20 March 2018). 
Dawkins R (2016) The selfish gene. Oxford: Oxford university press.

Dawkins R, Clements A, Dawkins R, Kidd D and Barnes R (2007) The Root of All Evil? IWC Media.

Day S (2007) On the game: women and sex work. London: Pluto Press.

Edlund L and Korn E (2002) A theory of prostitution. Journal of Political Economy 110:181-214.

Frith K and McElwee G (2009) Value-adding and value-extracting entrepreneurship at the margins. Journal of Small Business \& Entrepreneurship 22(1): 39-53.

Gaddefors J and Anderson AR (2017) Entrepreneursheep and context: when entrepreneurship is greater than entrepreneurs. International journal of entrepreneurial behavior \& research, 23(2): 267-278.

Gander K (2016) An Australian study has offered an insight into how women sex workers experience pleasure. Available at: www.independent.co.uk/life-style/lovesex/sex-worker-pleasure-with-clients-prostitution-gratification-intimacy-a 7484056.html (Accessed 19 March 2018)

Goffman E (1963) Stigma: Notes on a spoiled identity. Jenkins, JH \& Carpenter.

Graham J, Haidt J, Motyl M, Meindl P, Iskiwitch C and Mooijman M (2016) Moral Foundations Theory: On the advantages of moral pluralism over moral monism. In: Gray K and Graham J (eds). The Atlas of Moral Psychology: Mapping Good and Evil in the Mind. New York: Guilford Press, pp. 211-222.

Griffith JD, Capiola A Balotti B, Hart CL and Turner R (2016) Online Female Escort Advertisements: The Cost of Sex. Evolutionary Psychology 14(2): doi: 1474704916651270.

Harman G (2015) Moral relativism is moral realism. Philosophical Studies 172(4): 855-863.

Harris S (2011) The moral landscape: How science can determine human values. Simon and Schuster.

Harvey SB, Modini M, Joyce S, Milligan-Saville JS, Tan L, Mykletun A and Mitchell PB (2017) Can work make you mentally ill? A systematic meta-review of workrelated risk factors for common mental health problems. Occup Environ Med, 74:301-310

Heyl B S (1979) The madam as entrepreneur: Career management in house prostitution. New Brunswick, NJ: Transaction Books.

Hondro M (2013) Sex worker writes that prostitutes can enjoy their work. Available at: http://www.digitaljournal.com/article/358258 (Accessed 20 Feburary 2018) 
Killen M and Smetana J (Eds.) (2005). Handbook of moral development. Psychology Press.

Koken JA (2010) The meaning of the 'whore': How feminist theories on prostitution shape research on female sex workers. In: Ditmore M, Levy A and Willman A (eds) Sex work matters: Power and intimacy in the global sex industry. London: Zed Books.

Koken JA (2012) Independent female escort's strategies for coping with sex work related stigma. Sexuality \& Culture 16(3): 209-229.

Koken JA, Bimbi DS and Parsons JT (2009) Male and female escorts: A comparative analysis. In: Weitzer R (ed) Sex for sale prostitution, pornography and the sex industry (2nd ed.). London: Routledge.

Krüsi A, Kerr T, Taylor C, Rhodes T and Shannon K (2016) 'They won't change it back in their heads that we're trash': the intersection of sex work- related stigma and evolving policing strategies. Sociology of health \& illness 38(7): 1137-1150.

Lambek M (2012) Religion and morality. In: Fassin D (ed) A companion to moral anthropology, pp. 339-358.

Levy N (2014) Moral relativism: A short introduction. Oneworld Publications.

Lucas AM (2005) The Work of Sex Work: Elite Prostitutes' Vocational Orientations and Experiences, Deviant Behavior (26)6: 513-546.

Marlier E and Atkinson AB (2010) Indicators of poverty and social exclusion in a global context. Journal of Policy Analysis and Management 29(2): 285-304.

Maslach C and Goldberg J (1998) Prevention of burnout: New perspectives. Applied and preventive psychology 7(1): 63-74.

Maticka- Tyndale E, Lewis J and Street M (2005) Making a place for escort work: A case study. Journal of sex research 42(1): 46-53.

McElwee G, Smith R and Somerville P (2011) Theorising illegal rural enterprise: is everyone at it? International Journal of Rural Criminology 1(1): 40-62.

Mogilner C, Hershfield HE, and Aaker J (2018) Rethinking time: Implications for well- being. Consumer Psychology Review 1(1): 41-53.

Naci H and Ioannidis JP (2015) Evaluation of wellness determinants and interventions by citizen scientists. Jama 314(2): 121-122.

Netter JCG (2017) Why Be Reasonable? Political Liberalism, Moral Pluralism, and Deep Disagreement. $\mathrm{PhD}$ Thesis, University of Oxford, UK. 
Pajnik M (2015) Merchandizing Sex on the Web: Gender Bias in Profiling Actors and Services. Gender, Technology and Development 19(2): 181-203.

Peace R (2001) Social Exclusion: A Concept in Need of Definition?. Social Policy Journal of New Zealand 16: 17-36.

Picther J and Wijers M (2014) The impact of different regulatory models on the labour conditions, safety and welfare of indoor-based sex workers. Criminology and Criminal Justice 14(6): 549-564.

Pruitt MV and Krull AC (2010) Escort advertisements and male patronage of prostitutes. Deviant Behavior 32(1): 38-63.

Rekart ML (2005) Sex-work harm reduction. The Lancet, 366(9503): 2123-2134.

Horn J (2017) Evolution and the Epistemological Challenge to Moral Realism In: Ruse M and Richards RJ (eds) (2017). The Cambridge handbook of evolutionary ethics. Cambridge University Press, pp.114-128.

Ryff CD and Keyes CLM (1995) The structure of psychological well-being revisited. Journal of personality and social psychology 69(4): 719-727.

Sachs B. (2017) Explaining Right and Wrong: A New Moral Pluralism and Its Implications New York: Routledge.

Salin D (2015) Risk factors of workplace bullying for men and women: The role of the psychosocial and physical work environment. Scandinavian journal of psychology 56(1): 69-77.

Sallmann, J (2010) Living with stigma: Women's experiences of prostitution and substance use. Affilia: Journal of Women and Social Work 25: 146-159.

Sanders T, Connelly L and King LJ (2016) On our own terms: The working conditions of internet-based sex workers in the UK. Sociological Research Online 21(4): $1-14$.

Savitz L and Rosen L (1988) The sexuality of prostitutes: Sexual enjoyment reported by "streetwalkers". Journal of sex research 24(1): 200-208.

Sawyer, S Metz ME, Hinds JD and Brucker RA (2001) Attitudes towards prostitution among males: A “consumers' report”. Current Psychology 20(4): 363-376.

Scambler G and Paoli F (2008) Health work, female sex workers and HIV/AIDS: Global and local dimensions of stigma and deviance as barriers to effective interventions. Social science \& medicine 66(8): 1848-1862.

Seligman ME (2004) Authentic happiness: Using the new positive psychology to realize your potential for lasting fulfillment. New York: Simon and Schuster. 
Shaw WH and Barry V (2015) Moral issues in business. Cengage Learning.

Smith R and Christou ML (2009) Extracting value from their environment: Some observations on pimping and prostitution as entrepreneurship. Journal of Small Business and Entrepreneurship 22(1): 69-84.

Stryker K (2012) Some People Enjoy Being Prostitutes... Get Over It. Available at: www.huffingtonpost.com/kitty-stryker/some-people-enjoy-beingprostitutes_b_1405004.html (Accessed 19 February 2018)

Suikkanen J (2014). Morality and Well-Being. Encyclopedia of Quality of Life and Well-Being Research 4129-4133.

Sullivan B (2010) When (some) prostitution is legal: the impact of law reform on sex work in Australia. Journal of law and society 37(1): 85-104.

Van Brunschot EG, Sydie RA and Kull C (1999) Images of Prostitution: The Prostitute and Print Media. Women and Criminal Justice 10(4): 47-72.

Vaughn L (2015) Doing ethics: Moral reasoning and contemporary issues. USA: WW Norton \& Company.

Velleman JD (2015) Foundations for Moral Relativism: Second Expanded Edition. Open Book Publishers.

Wainwright, WJ (2017) Religion and morality. New York: Routledge.

Weitzer R (2000) Sex for Sale: Prostitution, Pornography, and the Sex Industry. New York: Routledge.

Weitzer R (2005) Flawed theory and method in studies of prostitution. Violence against women 11(7): 934-949.

Weitzer R (2006) Moral crusade against prostitution Society 43(3): 33-38.

Welter F (2011) Contextualizing entrepreneurship — conceptual challenges and ways forward. Entrepreneurship theory and practice 35(1): 165-184.

West A (2016) Applying metaethical and normative claims of moral relativism to (shareholder and stakeholder) models of corporate governance. Journal of business ethics 135(2): 199-215.

Williamson C and Baker LM (2009) Women in street-based prostitution: a typology of their work styles. Qualitative Social Work 8(1): 27-44. 
Figure 1

\section{Value-Adding}

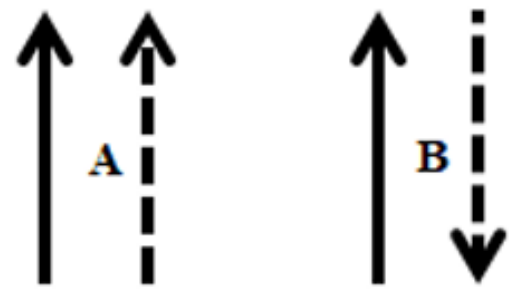

\section{Value-Extracting}

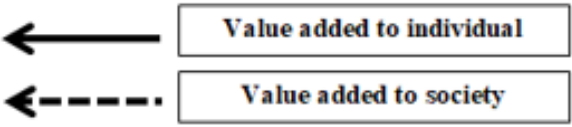

Value added to society

\section{Figure 2}

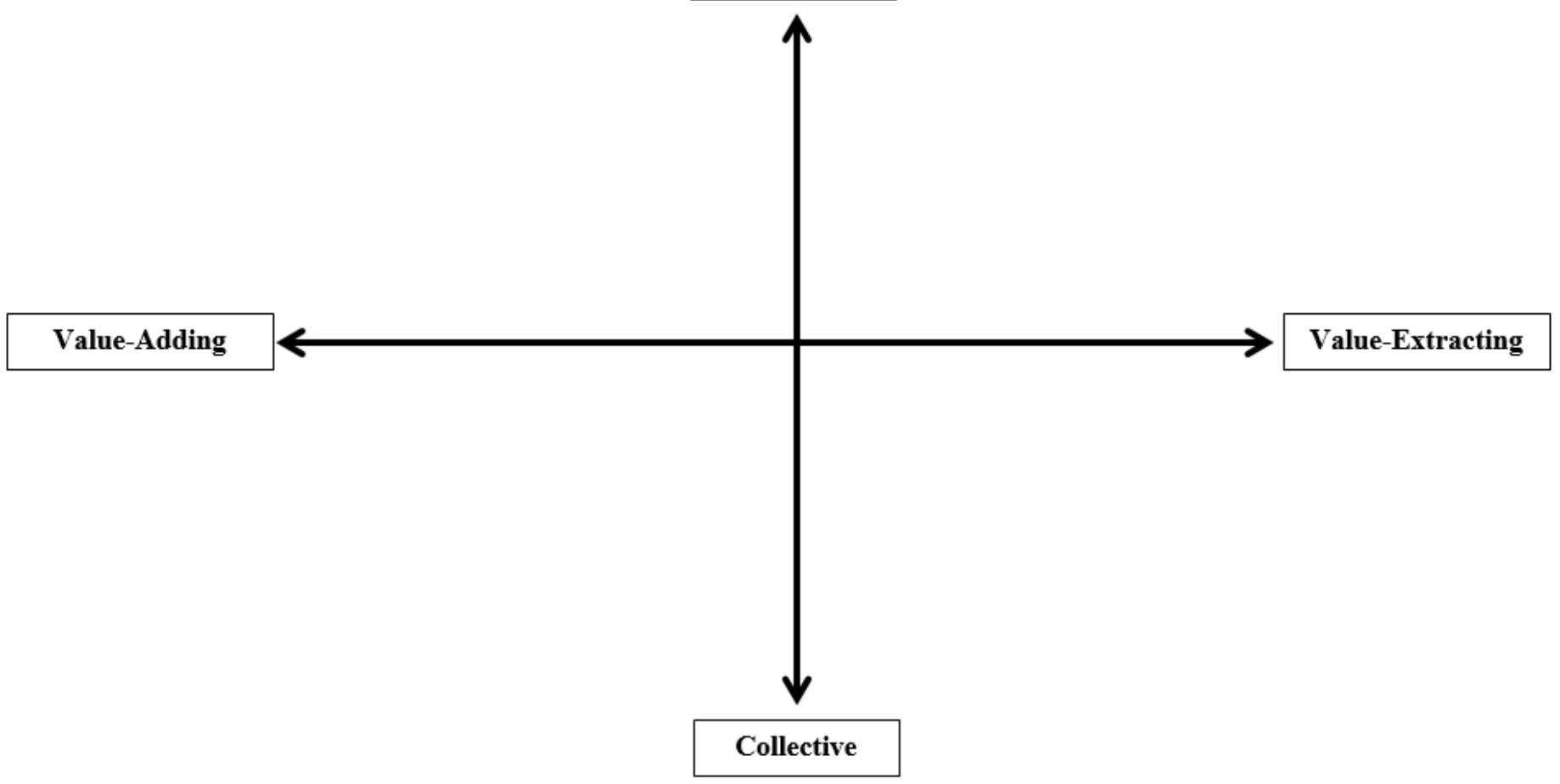

